\title{
REVIEW
}

\section{Iron deficiency in critically ill patients: highlighting the role of hepcidin}

\author{
Nicholas Heming', Philippe Montravers', Sigismond Lasocki* \\ This article is one of eleven reviews selected from the Annual Update in Intensive Care and Emergency Medicine 2011 (Springer Verlag) and \\ co-published as a series in Critical Care. Other articles in the series can be found online at http://ccforum.com/series/annual. Further \\ information about the Annual Update in Intensive Care and Emergency Medicine is available from http://www.springer.com/series/8901
}

\begin{abstract}
Introduction
Iron is a paradoxical element, essential for living organisms but also potentially toxic. Indeed, iron has the ability to readily accept and donate electrons, interconverting from soluble ferrous form $\left(\mathrm{Fe}^{2+}\right)$ to the insoluble ferric form $\left(\mathrm{Fe}^{3+}\right)$. This capacity allows iron to play a major role in oxygen transport (as the central part of hemoglobin) but also in electron transfer, nitrogen fixation or DNA synthesis, all essential reactions for living organisms. Indeed, iron deficiency is the main cause of anemia [1] as well as a cause of fatigue [2,3] and decreased effort capacity [4,5]. However, despite a high frequency of anemia among critically ill patients, with 60 to $66 \%$ being anemic at intensive care unit (ICU) admission [6,7], to date little is known about iron deficiency and iron metabolism in critically ill patients [8]. The interaction between inflammation and iron metabolism interferes with the usual iron metabolism variables and renders this metabolism difficult to investigate $[9,10]$.

The recent discovery of hepcidin (the master regulator of iron metabolism) has shed new light on the regulation of iron homeostasis and has helped our understanding of complex clinical situations, such as those observed in critically ill patients, where several regulatory circuits interfere with iron metabolism [11]. The purpose of this article is to review iron metabolism and anemia in critically ill patients as well as the role of hepcidin, and to discuss the indications for iron supplementation in these patients.
\end{abstract}

Iron metabolism overview and the role of hepcidin Although iron is essential for life, it may also be toxic because of its capacity to react with oxygen and to

*Correspondence: sigismond@lasocki.com

Université d'Angers. Département d'Anesthésie-Réanimation Chirurgicale, Centre Hospitalo-Universitaire d'Angers, Angers, France

Full list of author information is available at the end of the article promote the production of free radicals. This duality is found in human pathology: Iron deficiency (because of poor iron intake, abnormal blood losses etc...) presents with anemia and fatigue; whereas iron overload (mainly in hereditary hemochromatosis and following repeated blood transfusions) induces multiple organ dysfunctions (including liver fibrosis, cirrhosis, cardiomyopathy, diabetes...). This explains why iron homeostasis must be finely tuned to avoid both deficiency and excess.

Iron turnover in the organism occurs almost in a closed circuit (Fig. 1). Indeed, global iron turnover through losses (because of bleeding or cell desquamation) and dietary uptake (by duodenal cells) is only 1 to $2 \mathrm{mg}$ per day, compared to approximately 3 to $4 \mathrm{~g}$ of iron contained in the organism. In fact, most of the iron available for erythropoiesis comes from the catabolism of senescent red blood cells (RBCs) by macrophages in the reticuloendothelial system (called eythrophagocytosis). As shown in Figure 1, more than two-thirds of the body's iron content is incorporated into hemoglobin, either in bone marrow erythroid progenitors or in circulating RBCs. Once aged, these RBCs are internalized and hemoglobin is degraded in tissue macrophages. Iron is then transferred to the macrophage cytosol and either released into the blood flow or stored in ferritin molecules. In the plasma, transferrin binds newly released iron to allow its mobilization from storage sites (mainly the spleen and to a lesser extent the liver) to utilization sites (mainly the bone marrow). Erythropoiesis requires about 25 to $30 \mathrm{mg}$ of iron daily. It has to be stressed that the amount of iron present in the plasma at any time is small (about $3 \mathrm{mg}$ ) compared to the daily amount of iron needed for erythropoiesis. Iron metabolism is therefore finely tuned, with hepcidin being central to its regulation [12].

Hepcidin is a small 25 amino acid peptide mainly produced by the liver. It is produced as an 84 amino acid pre-pro-peptide. Pro-hepcidin has been shown to be

\section{Ciomed Central}

This work is subject to copyright. All rights are reserved, whether the whole or part of the material is concerned, specifically the rights of translation, reprinting, reuse of illustrations, recitation, broadcasting, reproduction on microfilm or in any other way, and storage in data banks. Duplication of this publication or parts thereof is permitted only under the provisions of the German Copyright Law of September 9, 1965 , in its current version, and permission for use must always be obtained from Springer-Verlag. Violations are liable for prosecution under the German Copyright Law. 


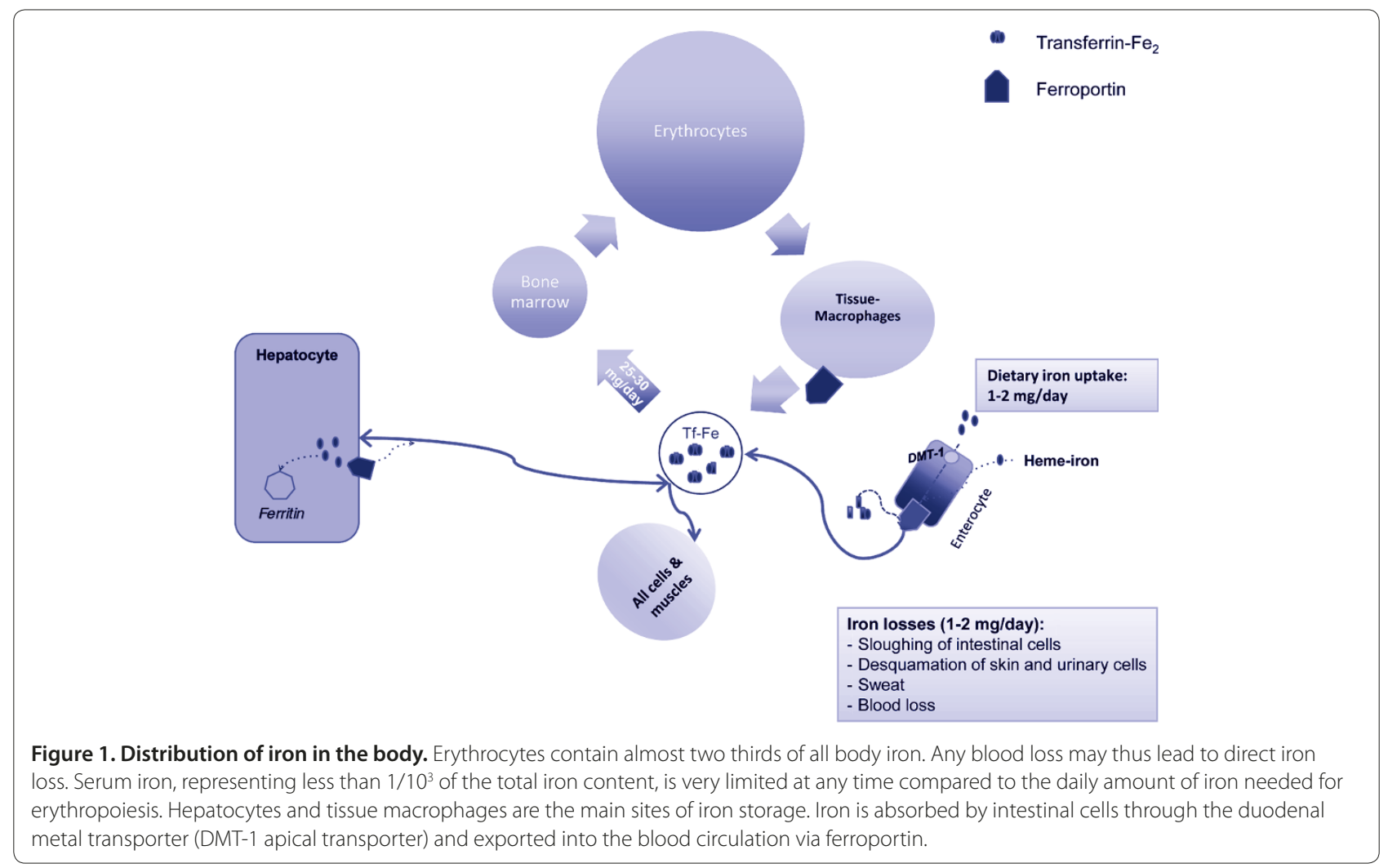

biologically inactive. Hepcidin acts by binding to ferroportin, which is the sole known iron exporter [13]. The binding of hepcidin to ferroportin induces its internalization and degradation in the cytosol, which prevents the release of intracellular iron [13]. Ferroportin is mainly expressed in macrophages and duodenal cells, allowing, respectively, iron recycling (after eythrophagocytosis) and iron absorption from the digestive lumen (after internalization of iron through natural resistance-associated macrophage protein [nRAMP]/duodenal metal transporter [DMT1]). Induction of hepcidin synthesis may thus lead to iron-restricted erythropoiesis (by inhibiting the release of iron from macrophages to the bone marrow) and to dietary iron deficiency (by inhibiting the uptake of iron from the digestive duodenal cells). Hepcidin acts as a 'hyposideremic' hormone, aimed at inhibiting iron absorption and reducing the level of iron in the blood.

Because hepcidin plays this central role in iron metabolism regulation, its synthesis is finely regulated (Fig. 2) [11,12]. Hepcidin synthesis is induced by iron overload and inflammation, whereas iron deficiency, hypoxia and erythroid expansion repress its synthesis. The molecular mechanisms implicated in these complex regulations are not fully understood (see [12] for review), but the induction of hepcidin synthesis by inflammation has been shown to be interleukin (IL)-6 dependent [14]. This interaction between hepcidin and inflammation makes hepcidin the principal agent responsible for the iron-restricted erythropoiesis observed during chronic diseases, ultimately leading to the anemia of chronic disease' (or anemia of inflammation) $[15,16]$. On the other hand, hepcidin synthesis is repressed by both iron deficiency and stimulation of erythropoiesis [11,12]. Although the precise mechanisms involved in the repression of hepcidin are not fully understood, it appears that matriptase 2, a membrane-bound serine protease expressed in hepatocytes, seems to play a key role in repressing hepcidin synthesis in iron deficiency conditions [17]. Repression of hepcidin by erythropoiesis stimulation is even less well understood, but seems to involve bone marrow erythropoietic activity rather than erythropoietin itself $[18,19]$. Hypoxia-inducible factor (HIF) or CCAAT enhancer binding protein-alpha pathways have also been proposed [12]. In human pathology, little is known. Growth differentiation factor 15, a member of the transforming growth factor (TGF)- $\beta$ family produced by late erythroblasts, has been found in high levels in patients with beta-thalassemia syndromes and has been shown to repress hepcidin synthesis [20]. These two opposite stimuli are found in the anemia of critically ill patients, as discussed below. 


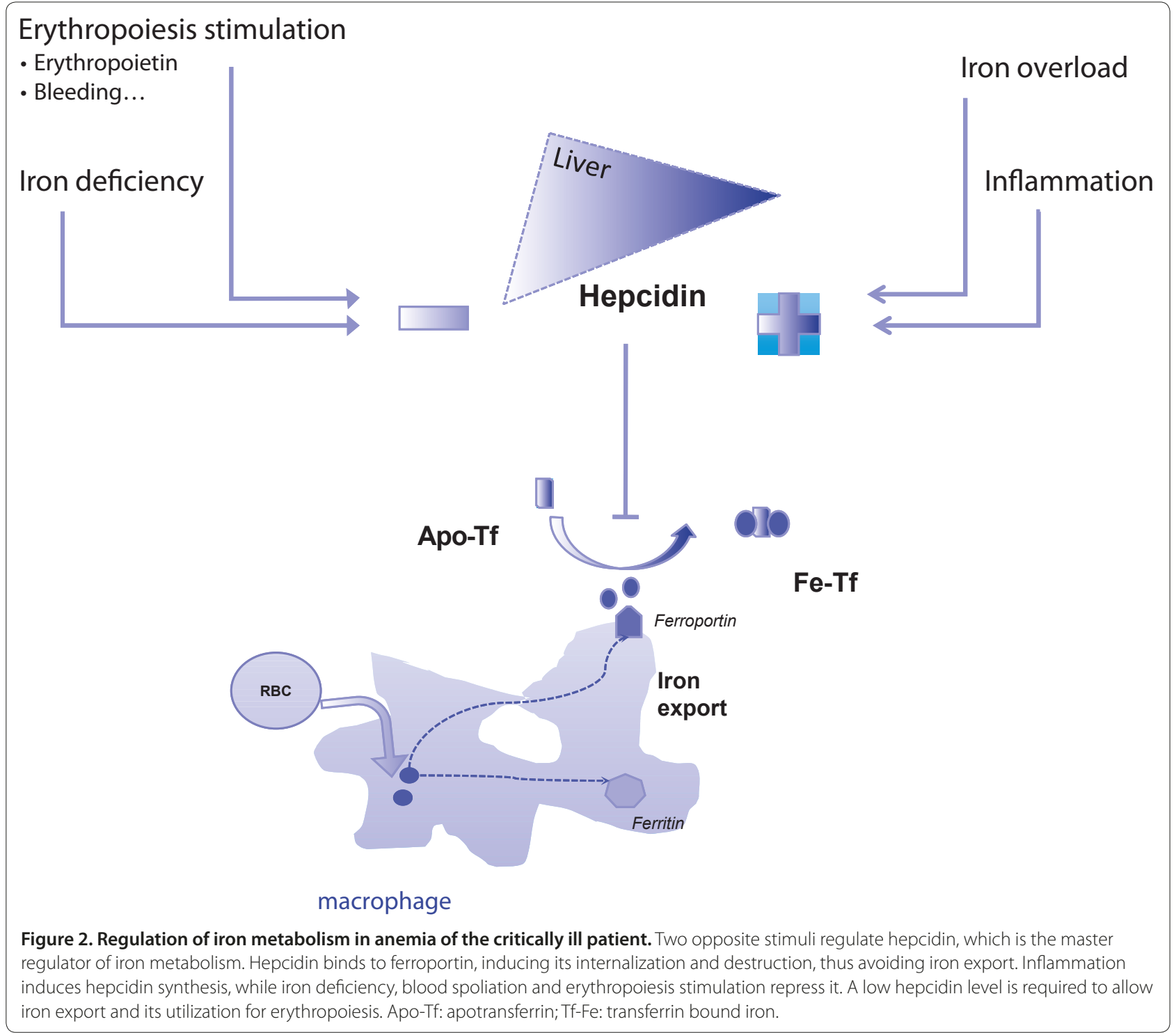

\section{Implication of iron metabolism in the anemia of the critically III: hepcidin as a diagnostic tool?}

Anemia is not only very frequent among critically ill patients, it is also associated with increased transfusion rates and worse outcomes (increased length of stay, increased mortality) [6,7]. However, recent recommendations have led to a decrease in transfusion triggers [21]. Nowadays, anemia is present at ICU discharge in at least $75 \%$ of all patients when considering their last measured hemoglobin levels [22]. Furthermore, anemia may also be prolonged after discharge, with a median time to recovery of 11 weeks and more than half of the patients still anemic 6 months after ICU discharge [23]. There is, therefore, need for a better understanding of the mechanisms of anemia in the critically ill and an evaluation of therapeutic options.
The two main contributing factors for anemia in the critically ill are inflammation and iron deficiency, which have opposite effects on iron metabolism (see above). Until recently, inflammation, rather than iron deficiency, was considered to play the major role. Indeed, the iron profile of critically ill patients constantly shows hallmarks of anemia of inflammation. However, this topic has not been considered a matter of great interest in the past, with few studies undertaken [9]. Inflammation is frequent in critical illness, whatever the underlying pathology. The anemia of critically ill patients is indeed similar to the anemia of inflammation, with blunted erythropoietic response and activation of $\mathrm{RBC}$ destruction by macrophages $[15,24]$. Low serum iron and high ferritin levels constitute the typical iron profile of critically ill patients and are indicative of an inflammatory iron profile $[25,26]$. 
Because ferritin synthesis is induced by inflammation (through IL-1) independently of the level of iron stores, elevated ferritin levels are no longer indicative of iron stores in the context of inflammation [10]. Thus, despite an iron profile that mimics iron overload (with high ferritin levels), iron deficiency may exist in these critically ill patients.

Indeed, daily blood losses are far from negligible, either through repeated blood sampling [6,27], surgical site bleeding, other invasive procedures (drainage, catheter placement, renal replacement therapy...) or occult bleeding [26]. The median blood loss for anemic critically ill patients has been estimated to be as high as $128 \mathrm{ml}$ per day [26]. This may represent a median iron loss as high as $64 \mathrm{mg}$ per day. As daily iron intake is less than 20 fold iron losses, iron deficiency could easily appear in critically ill patients.

Iron deficiency may thus coexist with inflammation. In addition, iron deficiency is not infrequent in the general population [28], and also in the elderly [3,29] or patients suffering from heart failure [30]. The frequency of iron deficiency on ICU admission may thus be around 35\% $[31,32]$. However, the diagnosis of iron deficiency is difficult in the context of inflammation because the usual indicators of iron deficiency are no longer valid $[9,10]$. Because inflammation induces ferritin synthesis, serum ferritin levels are no longer indicative of iron stores. New biological markers are thus required for the diagnosis of iron deficiency in the context of inflammation (Figure 3) [10]. Below are the main biological markers that can be used:

- Percentage of hypochromic RBCs. These hypochromic RBCs result from iron-restricted erythropoiesis. Schematically, a value of $>10 \%$ hypochromic erythrocytes (normal $<2.5 \%$ ) is indicative of ironrestricted erythropoiesis over the past 3 months (this being the RBC lifespan).

- Reticulocyte hemoglobin content. Reticulocyte hemoglobin content below $28 \mathrm{pg}$ is also indicative of ironrestricted erythropoiesis over the past 2 to 3 days (this being the lifespan of reticulocytes). Recently, a low reticulocyte hemoglobin content on admission was shown to be associated with higher transfusion rates in critically ill patients [32].

- Erythrocyte zinc protoporphyrin (ZPP). During erythropoiesis, Fe is normally incorporated into protoporphyrin IX to form heme. In iron deficiency, zinc is substituted for iron, leading to the formation of ZPP. Increased erythrocyte ZPP is thus indicative of iron deficiency.

- Soluble transferrin receptor (sTfR). Transferrin receptors allow the internalization of iron into erythroid progenitor. Their synthesis is increased as bone marrow erythropoietic activity increases. When iron supply is insufficient, a truncated form of transferrin receptor appears in the serum. sTfR is thus indicative of iron-deficiency anemia. This marker is widely proposed, however there is no gold standard for its measurement.

- $\mathrm{sTfR} / \log$ ferritin ratio (called the ferritin index). This is proposed as a marker to differentiate between anemia of inflammation and the combined situation of iron deficiency and anemia of inflammation, taking into account the "uncovered need for iron" on the one hand and the "iron stores" on the other [15].

Complex algorithms combining all these variables have been proposed for the diagnosis of iron deficiency in the presence of inflammation [10,15]; however, none are clinically validated and the cut-off values for each variable are unknown. Moreover, all but sTfR cannot be used after recent blood transfusion.

Being central to iron metabolism, hepcidin may be a marker of iron deficiency, even in the presence of inflammation. Indeed, using animal models, we and others have demonstrated that hepcidin can be repressed despite inflammation [33-35] and that this repression is associated with spleen iron mobilization [34]. These observations reinforce the concept that iron deficiency may coexist with anemia of inflammation [15]. Measurement of hepcidin concentrations may thus be helpful for the diagnosis of iron deficiency in the context of inflammation. Additionally, many hepcidin assays have been recently developed [36]. Most studies evaluating the use of hepcidin concentrations to diagnose iron deficiency during inflammation have used ELISA-based values showing virtually undetectable levels [35] or normal values $[37,38]$ of hepcidin despite inflammation (supposed to increase hepcidin synthesis). Measurement of hepcidin concentrations could be accurate in the diagnosis of iron deficiency in critically ill anemic patients using a cut-off value of less than $130 \mathrm{ng} / \mathrm{l}$ [38].

\section{Is there a place for iron supplementation or treatment in critically ill patients?}

Because iron deficiency may coexist with inflammation in critically ill patients $[9,10,32,38]$ and because iron may be mobilized from spleen stores in the presence of inflammation $[34,35]$, one could propose that iron be given to critically ill patients.

Because blood transfusion is not an option to fully correct the anemia in critically ill patients [6,21], the use of alternatives such as erythropoiesis-stimulating agents or iron has been suggested. Erythropoiesis-stimulating agents have already been studied in the critically ill. They have not been shown to be useful [39] and are beyond the scope of this review. In addition, iron deficiency may concern up to $40 \%$ of critically ill patients $[10,31,32,38]$. Iron may thus be needed not only for erythropoiesis but 


\begin{tabular}{|c|c|c|c|}
\hline & Iron deficiency & $\begin{array}{l}\text { Anemia of } \\
\text { inflammation }\end{array}$ & $\begin{array}{l}\text { Iron deficiency anc } \\
\text { inflammation }\end{array}$ \\
\hline Bone marrow iron & עצע & $y$ & עy \\
\hline Iron & עy & עצ & עy \\
\hline Transferrin & הת & עy & $N$ to $y$ \\
\hline Transferrin saturation & עy & עy & עy \\
\hline Ferritin & עy & הת & $N$ to $\pi$ \\
\hline $\begin{array}{l}\text { Percentage of hypochromic red blood } \\
\text { cells }\end{array}$ & הת & $\mathrm{N}$ to $\pi$ & הת \\
\hline Reticulocyte hemoglobin content & עצ & $\mathrm{N}$ or $\mathbf{y}$ & $y$ \\
\hline Erythrocyte zinc protoporphyrin & הת & $N$ to $\pi$ & הת \\
\hline sTfR & הת & עצ & $\pi$ \\
\hline sTfR/log ferritin & הת & $y$ & $\pi$ \\
\hline Hepcidin & עy & הת & $\mathrm{N}$ to $\mathbf{y}$ \\
\hline C-reactive Protein & $\mathrm{N}$ & תה & $\pi$ \\
\hline
\end{tabular}

sTfR: soluble transferrin receptor; N: normal; $\boldsymbol{y}$ : decreased; $\boldsymbol{Z}$ increased

Figure 3 Biological variable of iron metabolism.

also to correct all the disorders associated with iron deficiency, having been shown to improve functional capacity in women [40] and in cardiac patients [41]. However, iron is also a toxic compound with the ability to induce oxidative stress or to promote bacterial growth and may thus not be suitable in the ICU context. Indeed, free iron may induce oxidative stress through the Fenton reaction. Large amounts of iron, exceeding the transferrin iron-binding capacity, may thus be toxic by inducing the release of free iron and causing oxidative stress. This probably explains the increased mortality associated with large amounts of iron administration (around the DL50) observed in an animal model of peritonitis [42]. However, no increase in oxidative stress has been demonstrated in human practice [43]. There is also a link between iron and infection, with iron being needed for bacterial growth. The decrease in serum iron concentration may be a defense mechanism against bacterial proliferation. However, bacteria have developed mechanisms for iron acquisition including the release of siderophores. The respective affinity for iron between transferrin and siderophores is probably what matters [44]. In clinical studies, this link between iron and infection has essentially been supported by experimental data on microorganisms and retrospective studies in hemodialysis patients showing an association between hyperferritinemia and the likelihood of infection. However, available observational studies in postoperative or critically ill patients show no association between intravenous iron administration and risk of infection [45]. Furthermore, iron deficiency is associated with impaired immunity [46] and may, therefore, be responsible for increased susceptibility to infection [32] as well as being associated with increased length of stay in the ICU [31].

Iron may thus be suggested to correct iron deficiency, even in the presence of inflammation, similar to its proposed use in the treatment of patients with cancer-induced anemia $[15,47]$. Iron may be given using either intravenous or enteral routes. For the latter, ferrous iron is used. Iron absorption requires a mildly acidic medium (i.e., without concomitant use of proton pump inhibitors) and ascorbic acid. However, absorption may be reduced by inflammation because of the decrease in ferroportin levels induced by hepcidin, or because of frequent gastrointestinal adverse effects. The intravenous route allows administration of much higher doses with few adverse effects (with the notable exception of anaphylactic shock following iron dextran injections) and no difficulty of absorption. A recent meta-analysis showed that non-dextran iron was superior to enteral iron for the correction of anemia, with few adverse effects [48]. However, the only available study of intravenous iron showed no beneficial effect on erythropoiesis when used without erythropoiesis-stimulating agents [25]. The only study of iron deficiency treatment in critically ill patients is the study by Pieracci et al., which showed a reduced transfusion rate in patients with baseline iron deficiency treated with enteral iron supplementation (ferrous sulfate $325 \mathrm{mg}$ three times daily) [49]. In this study, oral iron supplementation was not associated with an increased risk of infection. 


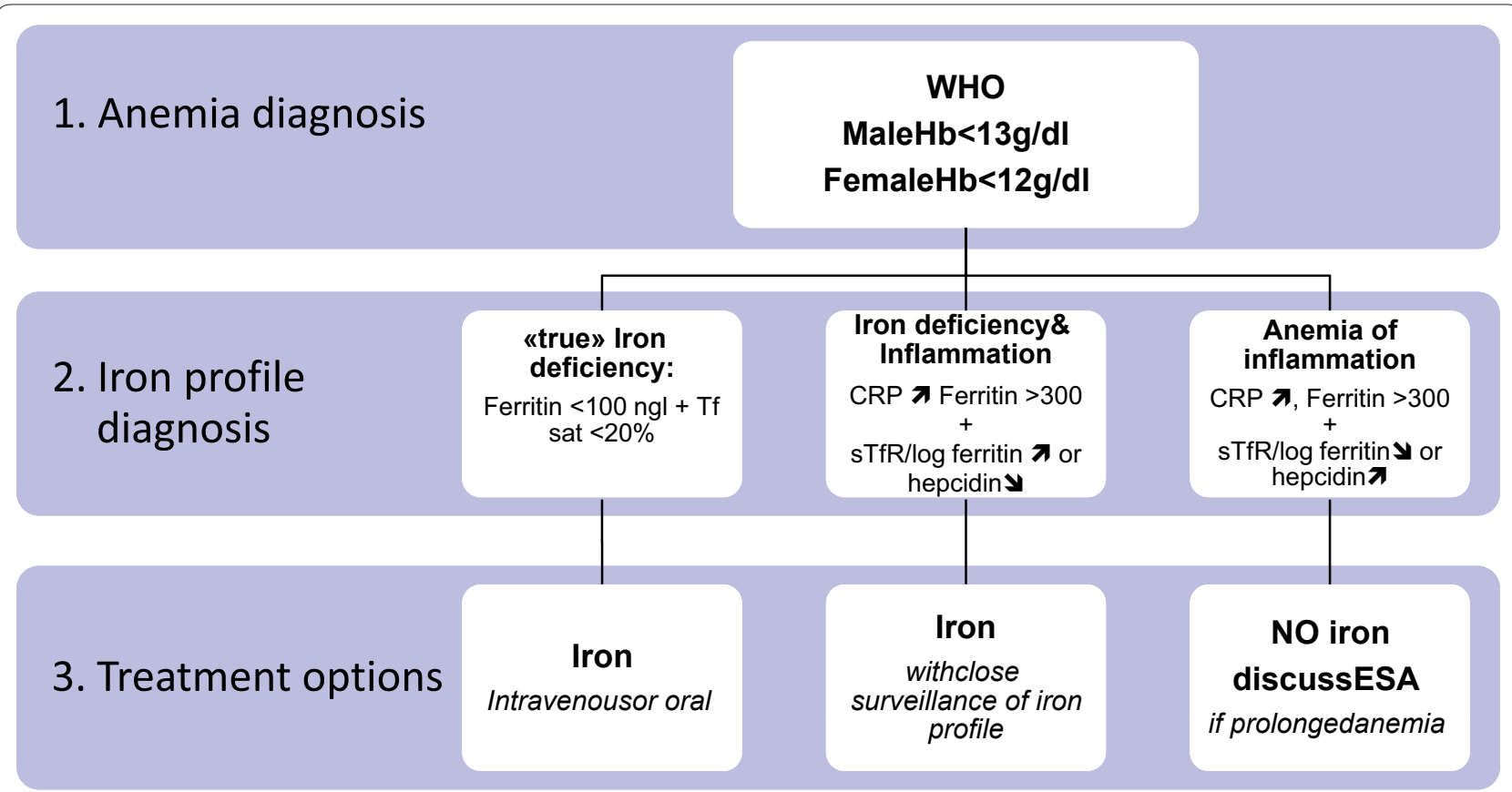

Figure 4. Algorithm for diagnosis and treatment of iron deficiency (proposal not yet supported by clinical trial evidence). ESA: erythropoiesis-stimulating agents; CRP: C-reactive protein; sTfR: soluble transferrin receptor.

Iron may therefore be proposed either to correct iron deficiency and/or to enhance the response to erythropoiesis-stimulating agents in critically ill patients, but further studies are needed to rule out the potential risks of iron treatment (i.e., oxidative stress induction, increased risk of infection) and to define the best route of administration. In Figure 4, we propose an algorithm for iron deficiency diagnosis and treatment. We believe that iron should be given to critically ill patients only in cases of iron deficiency, at best defined according to a low hepcidin level. The dose of iron needed may be assessed using the following formula:

\section{iron deficit $=$}

body weight $(\mathrm{kg}) \times($ target $\mathrm{Hb}-$ actual $\mathrm{Hb}) \times 2.4$.

Because elevated iron concentrations induce the synthesis of hepcidin, which in turn may reduce iron availability, the total dose of iron should be given using fractionated injections. Further clinical studies are needed to validate these propositions.

\section{Conclusion}

The discovery of hepcidin sheds new light on our knowledge of iron metabolism and may enable easier recognition of iron deficiency in the presence of inflammation in critically ill patients. This opens new areas of research exploring the role of iron treatment for these patients.
Competing interests

The authors declare that they have no competing interests.

\section{List of abbreviations used}

RBC: red blood cell; sTfR: soluble transferring receptor; ZPP: zinc protoporphyrin.

\section{Author details}

'Université Denis Diderot, Paris 7, Département d'Anesthésie-Réanimation Chirurgicale, Centre Hospitalo-Universitaire Bichat-Claude Bernard, Assistance

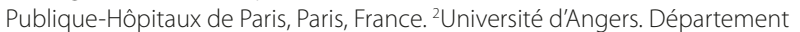
d'Anesthésie-Réanimation Chirurgicale, Centre Hospitalo-Universitaire d'Angers, Angers, France.

\section{Published: 22 March 2011}

\section{References}

1. Clark SF: Iron deficiency anemia. Nutr Clin Pract 2008, 23:128-141.

2. Patterson AJ, Brown WJ, Powers JR, Roberts DC: Iron deficiency, general health and fatigue: results from the Australian Longitudinal Study on Women's Health. Qual Life Res 2000, 9:491-497.

3. Schultz BM, Freedman ML: Iron deficiency in the elderly. Baillieres Clin Haematol 1987, 1:291-313.

4. Zhu YI, Haas JD: Iron depletion without anemia and physical performance in young women. Am J Clin Nutr 1997, 66:334-341.

5. Zhu YI, Haas JD: Altered metabolic response of iron-depleted nonanemic women during a 15-km time trial. J Appl Physiol 1998, 84:1768-1775.

6. Vincent JL, Baron JF, Reinhart K, et al:: Anemia and blood transfusion in critically ill patients. JAMA 2002, 288:1499-1507.

7. Corwin HL, Gettinger A, Pearl RG, et al:: The CRIT Study: Anemia and blood transfusion in the critically ill-current clinical practice in the United States. Crit Care Med 2004, 32:39-52.

8. Piagnerelli M, Vincent JL: Role of iron in anaemic critically ill patients: it's time to investigate! Crit Care 2004, 8:306-307.

9. Darveau M, Denault AY, Blais N, Notebaert E: Bench-to-bedside review: iron metabolism in critically ill patients. Crit Care 2004, 8:356-362.

10. Pieracci FM, Barie PS: Diagnosis and management of iron-related anemias in critical illness. Crit Care Med 2006, 34:1898-1905. 
11. Nicolas $G$, Chauvet $C$, Viatte $L$, et al:: The gene encoding the iron regulatory peptide hepcidin is regulated by anemia, hypoxia, and inflammation. J Clin Invest 2002, 110:1037-1044.

12. Hentze MW, Muckenthaler MU, Galy B, Camaschella C: Two to tango: regulation of Mammalian iron metabolism. Cell 2010, 142:24-38.

13. Nemeth E, Tuttle MS, Powelson J, et al:: Hepcidin regulates cellular iron efflux by binding to ferroportin and inducing its internalization. Science 2004, 306:2090-2093.

14. Nemeth E, Rivera S, Gabayan V, et al:: IL-6 mediates hypoferremia of inflammation by inducing the synthesis of the iron regulatory hormone hepcidin. J Clin Invest 2004, 113:1271 -1276.

15. Weiss G, Goodnough LT: Anemia of chronic disease. N Engl J Med 2005, 352:1011-1023.

16. Andrews NC: Anemia of inflammation: the cytokine-hepcidin link. J Clin Invest 2004, 113:1251-1253.

17. Ramsay AJ, Hooper JD, Folgueras AR, Velasco G, Lopez-Otin C: Matriptase-2 (TMPRSS6): a proteolytic regulator of iron homeostasis. Haematologica 2009, 94:849-849.

18. Pak M, Lopez MA, Gabayan V, Ganz T, Rivera S: Suppression of hepcidin during anemia requires erythropoietic activity. Blood 2006, 108:3730-3735.

19. Vokurka M, Krijt J, Sulc K, Necas E: Hepcidin mRNA levels in mouse liver respond to inhibition of erythropoiesis. Physiol Res 2006, 55:667-674.

20. Tanno T, Bhanu NV, Oneal PA, et al:: High levels of GDF15 in thalassemia suppress expression of the iron regulatory protein hepcidin. Nat Med 2007, 13:1096-1101

21. Hill SR, Carless PA, Henry DA, et al:: Transfusion thresholds and other strategies for guiding allogeneic red blood cell transfusion. Cochrane Dat Syst Rev 2002, CD002042.

22. Walsh TS, Lee RJ, Maciver CR, et al:: Anemia during and at discharge from intensive care: the impact of restrictive blood transfusion practice. Intensive Care Med 2006, 32:100-109.

23. Bateman AP, McArdle F, Walsh TS: Time course of anemia during six months follow up following intensive care discharge and factors associated with impaired recovery of erythropoiesis. Crit Care Med 2009, 37:1906-1912.

24. Corwin HL, Krantz SB: Anemia of the critically ill: "acute" anemia of chronic disease. Crit Care Med 2000, 28:3098-3099.

25. van Iperen CE, Gaillard CA, Kraaijenhagen RJ, Braam BG, Marx JJ, van de Wie $A$ : Response of erythropoiesis and iron metabolism to recombinant human erythropoietin in intensive care unit patients. Crit Care Med 2000, 28:2773-2778

26. von Ahsen N, Muller C, Serke S, Frei U, Eckardt KU: Important role of nondiagnostic blood loss and blunted erythropoietic response in the anemia of medical intensive care patients. Crit Care Med 1999 27:2630-2639.

27. Wisser D, van Ackern K, Knoll E, Wisser H, Bertsch T: Blood loss from laboratory tests. Clin Chem 2003, 49:1651-1655.

28. Looker AC, Dallman PR, Carroll MD, Gunter EW, Johnson CL: Prevalence of iron deficiency in the United States. JAMA 1997, 277:973-976.

29. Smieja MJ, Cook DJ, Hunt DL, Ali MA, Guyatt GH: Recognizing and investigating iron-deficiency anemia in hospitalized elderly people. CMA 1996, 155:691-696.

30. Jankowska EA, Rozentryt P, Witkowska A, et al:: Iron deficiency: an ominous sign in patients with systolic chronic heart failure. Eur Heart J 2010, 31:1872-1880

31. Bellamy MC, Gedney JA: Unrecognised iron deficiency in critical illness. Lancet 1998, 352:1903.

32. Fernandez R, Tubau I, Masip J, Munoz L, Roig I, Artigas A: Low reticulocyte hemoglobin content is associated with a higher blood transfusion rate in critically ill patients: a cohort study. Anesthesiology 2010, 112:1211-1215.
33. Huang H, Constante M, Layoun A, Santos MM: Contribution of STAT3 and SMAD4 pathways to the regulation of hepcidin by opposing stimuli. Blood 2009, 113:3593-3599.

34. Lasocki S, Millot S, Andrieu V, et al.:Phlebotomies or erythropoietin injections allow mobilization of iron stores in a mouse model mimicking intensive care anemia. Crit Care Med 2008, 36:2388-2394.

35. Theurl I, Aigner E, Theurl M, et al.: Regulation of iron homeostasis in anemia of chronic disease and iron deficiency anemia: diagnostic and therapeutic implications. Blood 2009, 113:5277-5286.

36. Kroot JJ, Kemna EH, Bansal SS, et al.: Results of the first international round robin for the quantification of urinary and plasma hepcidin assays: need for standardization. Haematologica 2009, 94:1748-1752.

37. Cheng PP, Jiao XY, Wang XH, Lin JH, Cai YM: Hepcidin expression in anemia of chronic disease and concomitant iron-deficiency anemia. Clin Exp Med in press.

38. Lasocki S, Baron G, Driss F, et al.: Diagnostic accuracy of serum hepcidin for iron deficiency in critically ill patients with anemia. Intensive Care Med 2010, 36:1044-1048

39. Zarychanski R, Turgeon AF, McIntyre L, Fergusson DA: Erythropoietinreceptor agonists in critically ill patients: a meta-analysis of randomized controlled trials. CMAJ 2007, 177:725-734.

40. Brutsaert TD, Hernandez-Cordero S, Rivera J, Viola T, Hughes G, Haas JD: Iron supplementation improves progressive fatigue resistance during dynamic knee extensor exercise in iron-depleted, nonanemic women. Am J Clin Nutr 2003, 77:441-448.

41. Anker SD, Comin Colet J, Filippatos G, et al:: Ferric carboxymaltose in patients with heart failure and iron deficiency. N Engl J Med 2009, 361:2436-2448.

42. Javadi P, Buchman TG, Stromberg PE, et al.: High-dose exogenous iron following cecal ligation and puncture increases mortality rate in mice and is associated with an increase in gut epithelial and splenic apoptosis. Crit Care Med 2004, 32:1178-1185

43. Driss F, Vrtovsnik F, Katsahian S, et al: Effects of intravenous polymaltose iron on oxidant stress and non-transferrin-bound iron in hemodialysis patients. Nephron Clin Pract 2005, 99:c63-c67.

44. Marx JJ: Iron and infection: competition between host and microbes for a precious element. Best Pract Res Clin Haematol 2002, 15:411-426.

45. Hoen B, Paul-Dauphin A, Kessler M: Intravenous iron administration does not significantly increase the risk of bacteremia in chronic hemodialysis patients. Clin Nephrol 2002, 57:457-461.

46. Dallman PR: Iron deficiency and the immune response. Am J Clin Nutr 1987 46:329-334

47. Auerbach M, Ballard H, Glaspy J: Clinical update: intravenous iron for anaemia. Lancet 2007, 369: 1502-1504.

48. Notebaert E, Chauny JM, Albert M, Fortier S, Leblanc N, Williamson DR: Shortterm benefits and risks of intravenous iron: a systematic review and metaanalysis. Transfusion 2007, 47:1905-1918.

49. Pieracci FM, Henderson P, Rodney JR, et al:: Randomized, double-blind, placebo-controlled trial of effects of enteral iron supplementation on anemia and risk of infection during surgical critical illness. Surg Infect (Larchmt) 2009, 10:9-19.

doi:10.1186/cc9992

Cite this article as: Heming $\mathrm{N}$ et al:. Iron deficiency in critically ill patients: highlighting the role of hepcidin. Critical Care 2011, 15:210. 